\title{
Application of Exosomes-Derived Mesenchymal Stem Cells in Treatment of Fungal Diseases: From Basic to Clinical Sciences
}

\author{
Seyedeh Ommolbanin Ghasemian* \\ Department of Veterinary, Behbahan Branch, Islamic Azad University Behbahan, Behbahan, Iran
}

OPEN ACCESS

Edited by:

Reza Shirazi,

UNSW Sydney, Australia

Reviewed by:

Mohammad Saied Salehi,

Shiraz University of Medical

Sciences, Iran

Nader Tanideh,

Shiraz University of Medical

Sciences, Iran

Mohammad Amin Behzadi, Auro Vaccines LLC, United States

*Correspondence:

Seyedeh Ommolbanin Ghasemian

ghasemian1249@yahoo.com

Specialty section:

This article was submitted to

Fungal Pathogenesis,

a section of the journal

Frontiers in Fungal Biology

Received: 30 July 2021

Accepted: 20 August 2021

Published: 30 September 2021

Citation:

Ghasemian SO (2021) Application of Exosomes-Derived Mesenchymal Stem Cells in Treatment of Fungal

Diseases: From Basic to Clinical

Sciences.

Front. Fungal Biol. 2:736093. doi: 10.3389/ffunb.2021.736093
Fungal diseases such as candidiasis are some of the deadliest diseases among immunocompromised patients. These fungi naturally exist on human skin and throughout the digestive system. When the microbiota balance becomes upset, these fungi become pathogenic and potentially lethal. At the pathogenesis of fungal diseases, host immune system response is diverse. At the early stages of fungal pathogenesis such as Candida albicans, it was shown that these fungi use the immune cells of the host body and cause malfunction the early induction of proinflammatory cytokines of the host body leading to a reduction in their numbers. However, at some stages of fungal diseases, the immune response is severe. Despite many treatments already being available, it seems that one of the best treatments could be an immune-stimulatory agent. Some of the subsets of MSCs and exosome-derived cells, as a cell-to-cell communicator agent, have many roles in the human body, including anti-inflammatory and immune-modulatory effects. However, the TLR4-primed and IL-17+ subsets of MSCs have been shown to have immune-stimulatory effects. These subsets of the MSCs produce pro-inflammatory cytokines and reduce immunosuppressive cytokines and chemokines. Thus, they could trigger inflammation and stop fungal pathogenesis. As some biological activities and molecules inherit elements of their exosomes from their maternal cells, the exosomederived TLR4-primed and IL-17+ subsets of MSCs could be a good candidate for fighting against fungal diseases. The applications of exosomes in human diseases are well-known and expanding. It is time to investigate the exosomes application in fungal diseases. In this review, the probable role of exosomes in treating fungal diseases is explored.

Keywords: fungi, exosome, mesenchymal stem cell, interleukin-17, toll-like receptor 4

\section{INTRODUCTION}

\section{Host-Fungi Interactions: Normal Flora or Pathogen?}

There are fungi in the human body that are known as normal flora (Prasad, 2007). This population of fungi is called fungal microbiota or mycobiota (Limon et al., 2017). Knowing these microbiotas, including mycobiota, is an important factor in host diseases and health (Limon et al., 2017). For many reasons, when the balance of these mycobiota is upset they can become a pathogen. Fungal diseases effect a quarter of the human population worldwide (Brown et al., 2012). However, while 
most of the fungal diseases are related to superficial skin conditions and can be treated locally, the systemic fungal infection could be so lethal (Brown et al., 2012; Vallabhaneni et al., 2016). These systemic fungal diseases usually occur because of diverse immune responses; especially in patients with immune system suppression (Pappas et al., 2018). There are lots of treatment option for systemic fungal diseases, but using them has limitations and usually brings poor outcomes (Scriven et al., 2017). It seems that one of the best choices to treat fungal diseases is reversing immune deficiency, which occurs in patients with immunosuppression (Scriven et al., 2017).

\section{Pathogenesis of Fungi and Host Immunity}

A previous study on $C$. albicans revealed that the host immune response to $C$. albicans is downregulated at early stages by pathogenic fungi (Halder et al., 2020). It was shown that the C. albicans attached to the C3 receptor of the monocytes by its $\beta$-glucan. Using this attachment to the monocytes, the fungi stimulate the monocytes to release extracellular vesicles contained transforming growth factor (TGF)- $\beta$. Using TGF- $\beta$ transporting vesicles, the fungi reduce immune response and cause anti-inflammatory effects at the early stages of fungi pathogenesis (Halder et al., 2020). Moreover, using TGF$\beta$ production, the fungi could reduce early production and induction of pro-inflammatory cytokines (Netea et al., 2002; Halder et al., 2020). This is how the fungi downregulate the host immune system in order to favor its existence and survival.

\section{Mesenchymal Stem/Stromal Cells (MSCs), Immunosuppressive or Immune-Stimulator?}

The MSCs are the progenitor/stem cells that have the capacity to differentiate into multilineage cells (Billing et al., 2016; de Castro et al., 2019). Due to their potential for differentiation, their immunomodulatory effect, and their regeneration capacity (Zhang et al., 2020a; Oh et al., 2021), they are widely used in treating injuries and some inflammatory disorders (Zhang et al., 2020a; Liao et al., 2021). Clinical studies have shown that because of the immunomodulatory function of some subsets of MSCs, MSC therapy could suppress the immune system and treat inflammatory and autoimmune diseases (Nauta and Fibbe, 2007; Yang et al., 2013). In detail, the MSCs, directly or indirectly, affect $\mathrm{T}$ cells and regulate them. The MSCs produce some chemokines and cytokines such as interleukin 10 (IL-10), prostaglandin $\mathrm{E}_{2}$ $\left(\mathrm{PGE}_{2}\right)$, nitric oxide (NO), TGF- $\beta$, indoleamine 2,3-dioxygenase (IDO), tumor necrosis factor-inducible gene 6 (TSG-6), and chemokine ligand 2 (Batten et al., 2006; Nauta and Fibbe, 2007; Yang et al., 2013). These molecules affect $\mathrm{CD} 4^{+} \mathrm{CD} 25^{+}$regulatory $\mathrm{T}$ ( T reg) with positive transcription factor Foxp3 and T helper 17 (Th17) cells' population and regulate them (Batten et al., 2006; Park et al., 2011; Yang et al., 2013; Bi et al., 2020). That's how MSCs downregulate the immune system in inflammatory and autoimmune diseases.

However, some previous studies have shown that another type of MSCs has an immune-stimulatory effect, and this

A
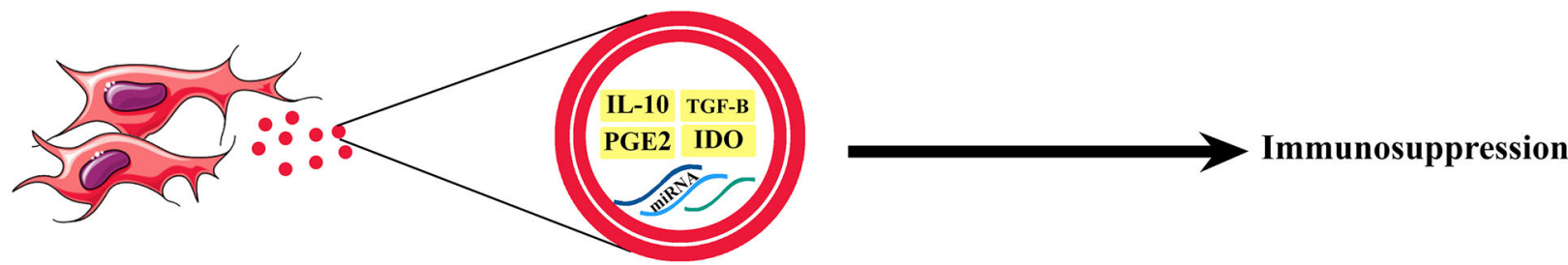

Mesenchymal stem cells (MSCs)

Exosomes-derived MSCs

B

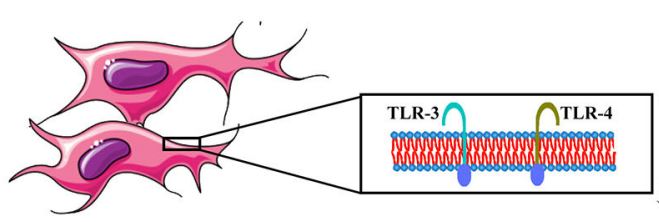

Mesenchymal stem cells (MSCs)

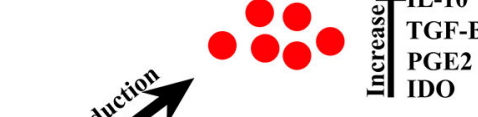

Exosomes-derived TLR3-primed MSCs

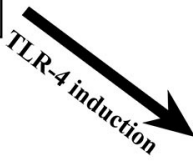

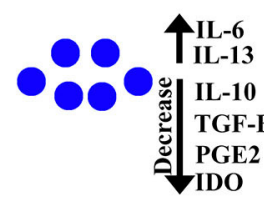

Exosomes-derived

TLR4-primed MSCs

\section{$\longrightarrow$ Immunosuppression}

\section{$\longrightarrow$ Immune-stimulator}

FIGURE 1 | The exosome-derived mesenchymal stem cells (MSCs) cytokines and chemokines content. (A) Normal MSCs. (B) TLR3-primed and TLR4-primed subtypes of MSCs. This figure shows chemokines and cytokines of exosomes-derived MSCs of different subtypes of MSCs and their biological activity. 


\section{TLR4-primed MSCs $+$ IL- $17^{+}$MSCs}

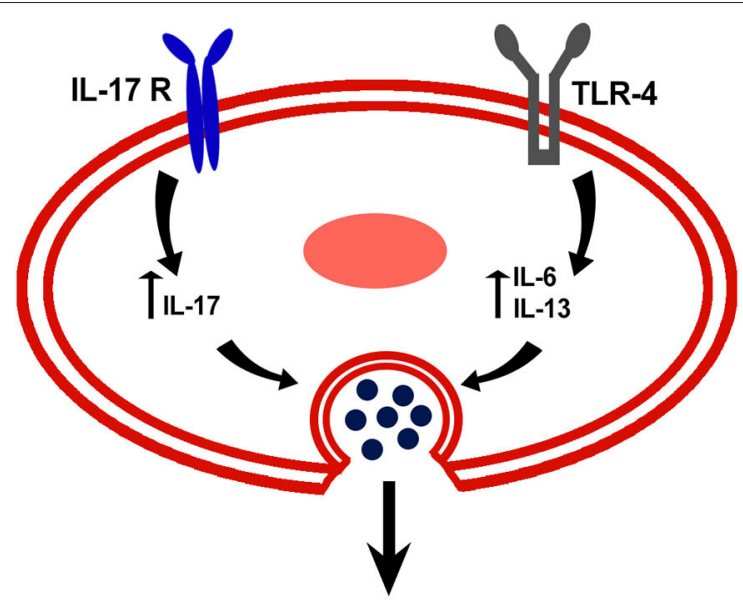

\section{Exosomes-derived MSCs}

Enriched with pro-inflammatory cytokines

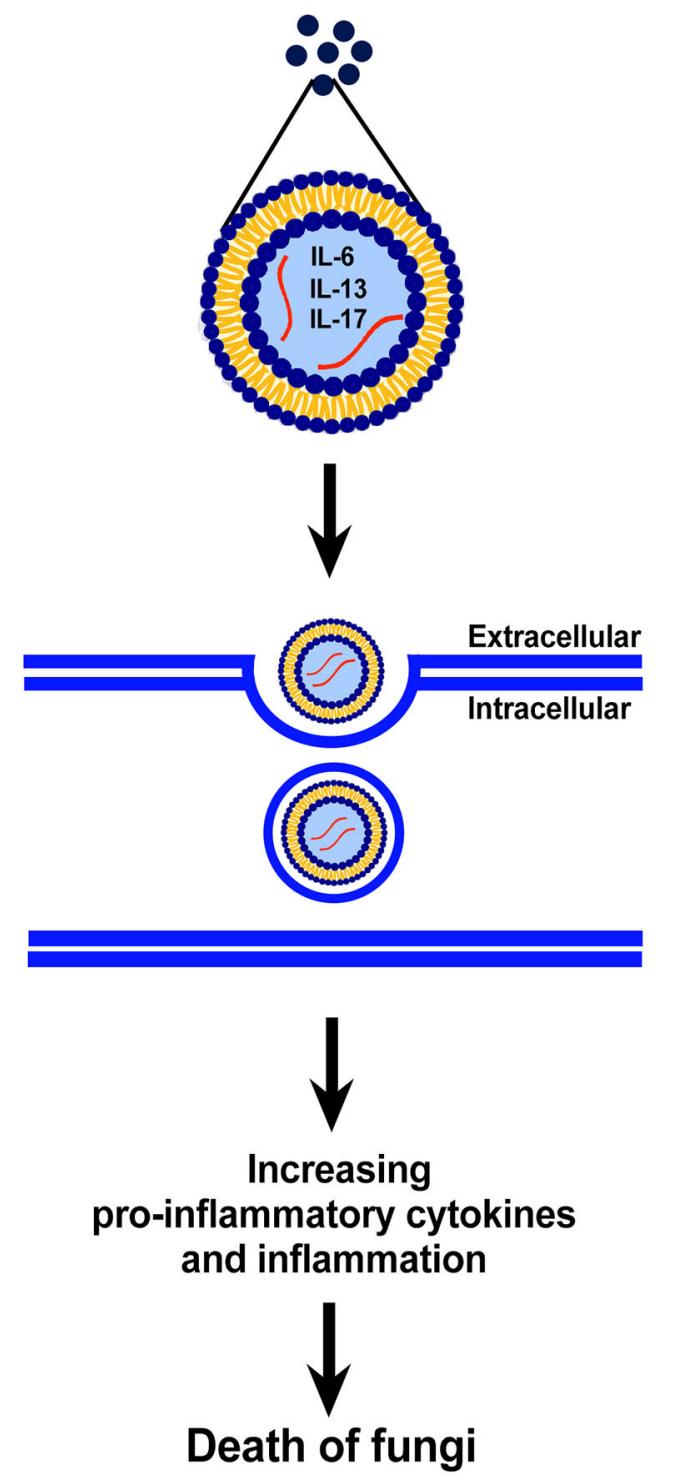

\section{Target cells}

Mainely $\mathrm{CD}^{+}$cells

FIGURE 2 | The exosome-derived TLR4-primed and IL-17+ MSCs. This figure shows the mechanism of anti-fungal effects of exosomes-derived new subtypes of MSCS. 
TABLE 1 | A list of companies producing various kinds of exosome-related products for therapeutic approaches.

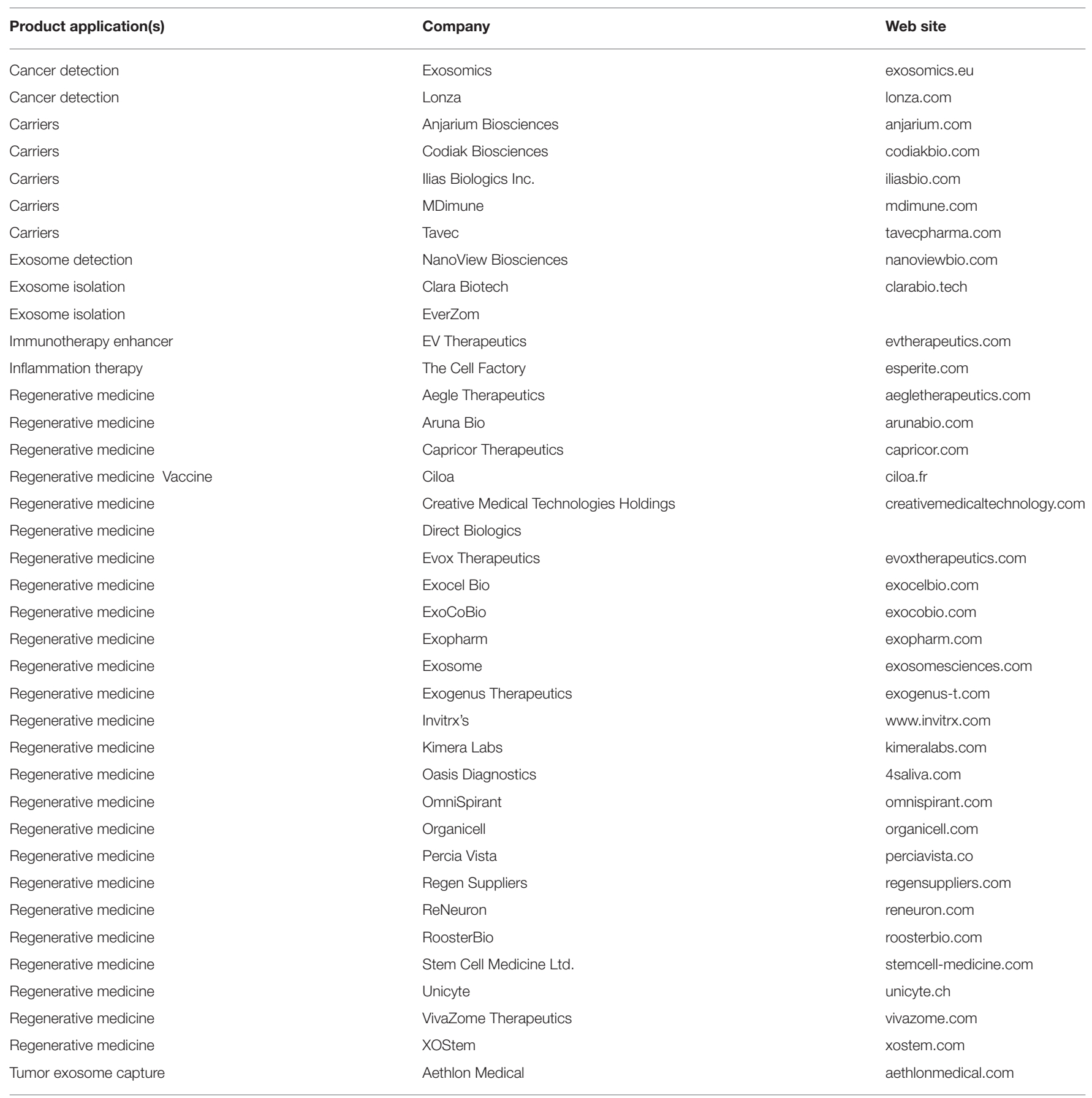

variety of the biological functions of MSCs depends on Tolllike receptors (TLRs) (Figure 1) (Waterman et al., 2010; Yang et al., 2013). It was shown that engagement of TLR-4 could enhance the production of pro-inflammatory mediators such as IL-17 and these MSCs are called TLR4-primed MSCs (Figure 1) (Waterman et al., 2010; Yang et al., 2013). In contrast, it was shown that TLR3-primed MSCs act as an immunomodulatory subset of MSCs (Waterman et al., 2010; Yang et al., 2013). The TLR4-primed MSCs, in contrast with TLR3-primed MSCs, was shown to increase expression of IL-6 and IL-13 as a pro-inflammatory cytokine and decrease IL-4, IDO, and $\mathrm{PGE}_{2}$ as an immunomodulatory cytokine and chemokine (Figure 1) (Waterman et al., 2010; Yang et al., 2013). IL-17 is a proinflammatory cytokine that plays a crucial role in intracellular and extracellular pathogenic defense (Yang et al., 2013; Schinocca et al., 2021). It was shown that a subpopulation of IL-17 ${ }^{+}$MSCs could inhibit C. albicans (Yang et al., 2013). Taken together, it might result that TLR4-primed and $\mathrm{IL}-17^{+}$subsets of MSCs 
TABLE 2 | Animal studies of exosomes-derived MSCs.

\begin{tabular}{|c|c|c|c|c|c|c|}
\hline Cell source & Therapeutics & Transplantation & Donor species & $\begin{array}{l}\text { Recipient } \\
\text { species }\end{array}$ & Biological effects & References \\
\hline Embryonic MSCs & Exosome & Xenotransplant & Human & Rat & Osteochondral regeneration promotion & Zhang et al., 2016 \\
\hline Adipose tissue-derived MSCs & Exosome & Xenotransplant & Human & Mouse & Atopic dermatitis alleviation & Cho et al., 2018 \\
\hline Adipose tissue-derived MSCs & Exosome & Xenotransplant & Human & Rat & Evaluation of exosomes cell toxicity & Ha et al., 2020 \\
\hline Bone marrow- derived MSCs & Exosome & Xenotransplant & Rat & Mouse & $\begin{array}{l}\text { Neuroprotective effect via inhibiting early } \\
\text { neuroinflammation }\end{array}$ & Ni et al., 2019 \\
\hline Wharton's jelly-derived MSCs & Exosome & Xenotransplant & Human & Rat & $\begin{array}{l}\text { Anti-inflammatory effects on microglia in } \\
\text { perinatal brain injury }\end{array}$ & Thomi et al., 2019 \\
\hline Umbilical cord-derived MSCs & Exosome & Xenotransplant & Human & Mouse & Acute liver failure alleviation & Jiang et al., 2019 \\
\hline Bone marrow- derived MSCs & Exosome & Xenotransplant & Rat & Mouse & $\begin{array}{l}\text { Inadequate promotion of bone } \\
\text { regeneration in type } 1 \text { diabetes }\end{array}$ & Zhu et al., 2019 \\
\hline Bone marrow- derived MSCs & Exosome & Allotransplant & Rabbit & Rabbit & Regulation of injured endometrium repair & Yao et al., 2019 \\
\hline Umbilical cord-derived MSCs & Exosome & Xenotransplant & Human & Mouse & Inflammatory bowel disease treatment & Mao et al., 2017 \\
\hline Adipose tissue-derived MSCs & Exosome & Allotransplant & Rat & Rat & $\begin{array}{l}\text { Promotion of endometrium regeneration } \\
\text { in rats with intrauterine adhesion }\end{array}$ & Zhao et al., 2020 \\
\hline Placental- derived MSCs & Exosome & Xenotransplant & Human & Mouse & $\begin{array}{l}\text { Enhancement of angiogenesis and } \\
\text { improvement of neurologic function }\end{array}$ & Zhang et al., 2020b \\
\hline Umbilical cord-derived MSCs & Exosome & Xenotransplant & Human & Mouse & $\begin{array}{l}\text { Inhibition of silica-induced PF and } \\
\text { improve lung function }\end{array}$ & Xu et al., $2020 a$ \\
\hline $\begin{array}{l}\text { Bone marrow- derived MSCs } \\
\text { Adipose tissue-derived MSCs }\end{array}$ & Exosome & - & - & Rat & $\begin{array}{l}\text { Improvement of erectile dysfunction in } \\
\text { bilateral cavernous nerve injury }\end{array}$ & Li et al., 2018 \\
\hline Bone marrow- derived MSCs & Exosome & Allotransplant & Rat & Rat & $\begin{array}{l}\text { Rescuing myocardial } \\
\text { ischaemia/reperfusion injury }\end{array}$ & Liu et al., 2017 \\
\hline Umbilical cord-derived MSCs & Exosome & Xenotransplant & Human & Rat & $\begin{array}{l}\text { Inhibition of vein graft neointimal } \\
\text { hyperplasia and acceleration of } \\
\text { reendothelialization }\end{array}$ & Qu et al., 2020 \\
\hline Adipose tissue-derived MSCs & Exosome & Allotransplant & Mouse & Mouse & $\begin{array}{l}\text { Exo-circAkap7, a potential treatment for } \\
\text { cerebral ischemic injury. }\end{array}$ & Xu et al., 2020b \\
\hline Bone marrow- derived MSCs & Exosome & Xenotransplant & Rat & Guinea pig & $\begin{array}{l}\text { Reduction of demyelination and } \\
\text { neuroinflammation in an immune-induced } \\
\text { demyelination model }\end{array}$ & Li et al., 2019 \\
\hline Bone marrow- derived MSCs & Exosome & Allotransplant & Rat & Rat & $\begin{array}{l}\text { Promotion of immunotolerance and } \\
\text { prolong the survival of cardiac allografts }\end{array}$ & He et al., 2018 \\
\hline
\end{tabular}

MSCs, mesenchymal stem cells.

could be good candidates for fighting against fungal diseases (Figures 1, 2) (Waterman et al., 2010; Yang et al., 2013).

\section{The Extracellular Vesicles (EVs) and Its Classification}

EVs have the main role in cell-to-cell communications (Andaloussi et al., 2013), and have been observed in both eukaryotes and prokaryotes (Ellis and Kuehn, 2010; Andaloussi et al., 2013). Studies have shown that the EVs could transfer the proteins and nucleic acids by its bilayer membrane (Lee et al., 2012; Ratajczak et al., 2012). Due to their potential for transferring proteins and nucleic acids, EVs are used widely as drug delivery agents (Elsharkasy et al., 2020). In order to best discuss the biological roles of EVs, here we describe the classification of EVs. The EVs based on their cellular origin, biological function, biogenesis, and size classified into three main groups: exosomes, microvesicles, and apoptotic bodies (Andaloussi et al., 2013; Yáñez et al., 2015). The two first particles, the exosomes and microvesicles, have been shown to have therapeutic effects (Wang et al., 2015; Phinney and Pittenger, 2017). The exosomes, with $40-120 \mathrm{~nm}$ in size, are generated by the endolysosomal pathway. In contrast with exosomes, the microvesicles are generated by budding from the cell surface (Andaloussi et al., 2013; Raposo and Stoorvogel, 2013). The exosomes with their non-sized particles, composed of a bilayer membrane and cytoplasm, contained mRNA, miRNA, and other RNAs' generated from the parent cell (Andaloussi et al., 2013; Raposo and Stoorvogel, 2013).

\section{The Exosomes-Derived MSCs and Their Biological Activity}

Stem cells, especially mesenchymal stem cells, were used widely in past decades as a candidate for therapies of various diseases. In recent years, exosome-derived stem cells were substitutionally used for regenerative and immune-therapy as a cell-free therapy (Ji et al., 2019; Qiu et al., 2020). Previous studies have shown that the exosome-derived stem cells contained various bioactive molecules, especially proteins and microRNAs which originated 
from maternal cells (Baharlooi et al., 2020; Ma et al., 2020). These exosomes were shown to have some biological effects inherited from their maternal cells (Baharlooi et al., 2020). For instance, the exosome-derived MSCs displayed angiogenesis, regeneration, and especially anti-inflammatory effects (Baharlooi et al., 2020). Moreover, it was shown that these exosomes could carry various cytokines and chemokines originated and produced by the maternal cell (Di Trapani et al., 2016; Baharlooi et al., 2020). So, here we can hypothesize that the TLR4-primed MSCs could pass their pro-inflammatory cytokines and chemokines into exosomes derived from them. Exosomes-derived TLR4primed MSCs could trigger the host immune system to start inflammation against fungal pathogens and fight against the immunosuppressive path of fungi.

\section{DISCUSSION}

The MSCs have been used in the treatment of microbial diseases for the past decades (Zhou and $\mathrm{Xu}, 2020$ ). In most microbial diseases, the host-microbe interactions cause inflammation, which damaged host tissues (Qiu et al., 2020). Some of the subsets of MSCs, using the production of anti-inflammatory and immunomodulatory cytokines and chemokines, serve to downregulate the host immune system and reduce host tissue damages (Waterman et al., 2010; Baharlooi et al., 2020). That is why the MSCs were widely used in past decades for inflammatory and autoimmune diseases treatment. Among all microbial diseases, the pathogenesis of fungal diseases is more complicated. The fungi pathogen at the first stages of pathogenesis downregulates the immune system of the host body using TGF- $\beta$-transporting vesicles produced by induced monocytes (Netea et al., 2002; Halder et al., 2020). Using immunosuppression, the pathogen could survive better.

In recent years, it was noticed that the different subtypes of MSCs could show different biological activities (Waterman et al., 2010; Yang et al., 2013; Baharlooi et al., 2020). It was shown that induction of TLR-4 of MSCs could enhance its immune-stimulatory activity using the production of proinflammatory cytokines and chemokines (Waterman et al., 2010; Yang et al., 2013). As is obvious, in contrast with other microbial pathogenesis (Nauta and Fibbe, 2007) the fungal pathogen stops inflammation and downregulates the host immune system; so to fight that, the immune system needs to be upregulated and made able to inflame (Waterman et al., 2010; Yang et al., 2013). It was shown that the TLR4primed and $\mathrm{IL}_{-}-17^{+}$subsets of MSCs could express proinflammatory cytokines and chemokines, which could lead to inflammation (Waterman et al., 2010; Yang et al., 2013). These subtypes of MSCs could be an agent for fungal diseases treatment.

As is known, cell therapy has some challenges for human diseases therapy (Choi and Lee, 2016). The exosomes, as a cell-free therapy, solve most of the problems of cell therapy
(Choi and Lee, 2016). Unlike a cell therapy, the exosomes are capable of crossing the blood-brain barrier and traveling through capillaries, and owing to their small sizes they are safe from reticuloendothelial system clearing (Li and Huang, 2009; Choi and Lee, 2016; Baharlooi et al., 2020). Moreover, as the exosomes inherited some of the molecules and biological activity of their maternal cells, they could be a good substitute for cell therapy (Di Trapani et al., 2016; Baharlooi et al., 2020; Ma et al., 2020). The exosome-derived MSCs showed to have anti-inflammatory and regenerative effects, the same as their maternal cells (Baharlooi et al., 2020). Several companies are developing exosome-derived products to take advantage of these applications, which suggests that in the future exosomes and their derived applications will be a viable choice for various disease therapies (Table 1).

As the maternal cell produces anti-inflammatory cytokines and chemokines, these molecules could pass into the exosomes (Wang et al., 2015; Baharlooi et al., 2020). Based on previous results, it could be hypothesized that the TLR4-primed and IL$17^{+}$subsets of MSCs could pass its produced pro-inflammatory cytokines and its immune-stimulatory activity into its exosomes. These exosomes could be a treatment for fungal pathogenesis.

During the past decade, many preclinical studies of exosomes have been conducted. Some of these studies have been shown in Table 2. These studies demonstrated that exosomes-derived MSCs could have anti-inflammatory, anti-atopic dermatitis, anti-neurodegenerative, anti-liver fibrosis biological activities, and so on (Li et al., 2013; Cho et al., 2018; Lee et al., 2018; Gowen et al., 2020). Despite many preclinical studies of exosomes, clinical studies of the MSCs-derived exosomes are few (Gowen et al., 2020). The MSCs-derived exosomes were used in previous clinical studies to treat diseases such as graft-versus-host disease (Kordelas et al., 2014), chronic kidney disease with grade III and IV (Nassar et al., 2016), type II diabetes (Sun et al., 2018), and prevention of the onset of type-1 diabetes via suppression of immune system and induction of beta cells regeneration (Ezquer et al., 2012). There are also several studies which have not yet been published.

However, stem cell-derived exosomes have some limitations for clinical studies. For instance, large-scale exosome production is lacking; large-scale exosome quantifications methods with rapid and accurate results, and determination of exosomes' contents with high accuracy also present dificulties (Gowen et al., 2020). Moreover, the pharmacokinetics, pathways, targets and mechanisms of action of the exosomes in the human body still remain unknown. Additionally, more studies are needed to evaluate the correct dosage of the exosomes for clinical studies in order to prevent possible toxicities (Gowen et al., 2020).

\section{AUTHOR CONTRIBUTIONS}

SOG: data collection, manuscript writing, idea conception, study design, and approved the final version. 


\section{REFERENCES}

Andaloussi, S. E., Mäger, I., Breakefield, X. O., and Wood, M. J. (2013). Extracellular vesicles: biology and emerging therapeutic opportunities. Nat. Rev. Drug Disc. 12:2. doi: 10.1038/nrd3978

Baharlooi, H., Azimi, M., Salehi, Z., and Izad, M. (2020). Mesenchymal stem cellderived exosomes: a promising therapeutic ace card to address autoimmune diseases. Int. J. Stem Cells 13:4. doi: 10.15283/ijsc19108

Batten, P., Sarathchandra, P., Antoniw, J. W., Tay, S. S., Lowdell, M. W., Taylor, P. M., et al. (2006). Human mesenchymal stem cells induce T cell anergy and downregulate $\mathrm{T}$ cell allo-responses via the TH2 pathway: relevance to tissue engineering human heart valves. Tissue Eng. 12:5. doi: $10.1089 /$ ten.2006.12.2263

Bi, Y., Lin, X., Liang, H., Yang, D., Zhang, X., Ke, J., et al. (2020). Human adipose tissue-derived mesenchymal stem cells in Parkinson's disease: inhibition of $\mathrm{T}$ helper 17 cell differentiation and regulation of immune balance towards a regulatory T cell phenotype. Clin. Intervent. Aging 15:6. doi: 10.2147/CIA.S259762

Billing, A. M., Hamidane, H. B., Dib, S. S., Cotton, R. J., Bhagwat, A. M., Kumar, P., et al. (2016). Comprehensive transcriptomic and proteomic characterization of human mesenchymal stem cells reveals source specific cellular markers. Sci. Rep. 6, 1-15. doi: 10.1038/srep,21507

Brown, G. D., Denning, D. W., Gow, N. A., Levitz, S. M., Netea, M. G., and White, T. C. (2012). Hidden killers: human fungal infections. Sci. Transl. Med. 4, 1-4. doi: $10.1126 /$ scitranslmed.3004404

Cho, B. S., Kim, J. O., Ha, D. H., and Yi, Y. W. (2018). Exosomes derived from human adipose tissue-derived mesenchymal stem cells alleviate atopic dermatitis. Stem Cell Res. Ther. 9, 1-5. doi: 10.1186/s13287-018-0939-5

Choi, H., and Lee, D. S. (2016). Illuminating the physiology of extracellular vesicles. Stem Cell Res. Ther. 7, 1-7. doi: 10.1186/s13287-016-0316-1

de Castro, L. L., Lopes-Pacheco, M., Weiss, D. J., Cruz, F. F., and Rocco, P. R. M. (2019). Current understanding of the immunosuppressive properties of mesenchymal stromal cells. J. Mol. Med. 97:2. doi: 10.1007/s00109-019-01776-y

Di Trapani, M., Bassi, G., Midolo, M., Gatti, A., Kamga, P. T., Cassaro, A., et al. (2016). Differential and transferable modulatory effects of mesenchymal stromal cell-derived extracellular vesicles on T, B and NK cell functions. Sci. Rep. 6:7. doi: 10.1038/srep24120

Ellis, T. N., and Kuehn, M. J. (2010). Virulence and immunomodulatory roles of bacterial outer membrane vesicles. Microbiol. Mol. Biol. Rev. 74, 1-4. doi: 10.1128/MMBR.00031-09

Elsharkasy, O. M., Nordin, J. Z., Hagey, D. W., de Jong, O. G., Schiffelers, R. M., Andaloussi, S. E., et al. (2020). Extracellular vesicles as drug delivery systems: why and how? Adv. Drug Deliv. Rev. 159:6. doi: 10.1016/j.addr.2020. 04.004

Ezquer, F., Ezquer, M., Contador, D., Ricca, M., Simon, V., and Conget, P. (2012). The antidiabetic effect of mesenchymal stem cells is unrelated to their transdifferentiation potential but to their capability to restore Th1/Th2 balance and to modify the pancreatic microenvironment. Stem Cells 30, 1664-1674. doi: $10.1002 /$ stem. 1132

Gowen, A., Shahjin, F., Chand, S., Odegaard, K. E., and Yelamanchili, S. V. (2020). Mesenchymal stem cell-derived extracellular vesicles: challenges in clinical applications. Front. Cell Dev. Biol. 8, 1-8. doi: 10.3389/fcell.2020.00149

Ha, D. H., Kim, S.-D., Lee, J., Kwon, H. H., Park, G.-H., Yang, S. H., et al. (2020). Toxicological evaluation of exosomes derived from human adipose tissue-derived mesenchymal stem/stromal cells. Regulat. Toxicol. Pharmacol. 115:104686. doi: 10.1016/j.yrtph.2020.104686

Halder, L. D., Jo, E. A., Hasan, M. Z., Ferreira-Gomes, M., Krüger, T., Westermann, M., et al. (2020). Immune modulation by complement receptor 3-dependent human monocyte TGF- $\beta 1$-transporting vesicles. Nat. Commun. 11, 1-19. doi: 10.1038/s41467-020-16241-5

He, J.-G., Xie, Q.-L., Li, B.-B., Zhou, L., and Yan, D. (2018). Exosomes derived from IDO1-overexpressing rat bone marrow mesenchymal stem cells promote immunotolerance of cardiac allografts. Cell Transpl. 27, 1657-1683. doi: $10.1177 / 0963689718805375$

Ji, L., Bao, L., Gu, Z., Zhou, Q., Liang, Y., Zheng, Y., et al. (2019). Comparison of immunomodulatory properties of exosomes derived from bone marrow mesenchymal stem cells and dental pulp stem cells. Immunol. Res. 67, 1-10. doi: 10.1007/s12026-019-09088-6
Jiang, L., Zhang, S., Hu, H., Yang, J., Wang, X., Ma, Y., et al. (2019). Exosomes derived from human umbilical cord mesenchymal stem cells alleviate acute liver failure by reducing the activity of the NLRP3 inflammasome in macrophages. Biochem. Biophys. Res. Commun. 508, 735-741. doi: 10.1016/j.bbrc.2018.11.189

Kordelas, L., Rebmann, V., Ludwig, A., Radtke, S., Ruesing, J., Doeppner, T., et al. (2014). MSC-derived exosomes: a novel tool to treat therapy-refractory graft-versus-host disease. Leukemia 28, 970-973. doi: 10.1038/leu.2014.41

Lee, M., Ban, J.-J., Yang, S., Im, W., and Kim, M. (2018). The exosome of adiposederived stem cells reduces $\beta$-amyloid pathology and apoptosis of neuronal cells derived from the transgenic mouse model of Alzheimer's disease. Brain Res. 1691, 87-93. doi: 10.1016/j.brainres.2018.03.034

Lee, Y., El Andaloussi, S., and Wood, M. J. (2012). Exosomes and microvesicles: extracellular vesicles for genetic information transfer and gene therapy. Hum. Mol. Genet. 21:5. doi: 10.1093/hmg/dds317

Li, M., Lei, H., Xu, Y., Li, H., Yang, B., Yu, C., et al. (2018). Exosomes derived from mesenchymal stem cells exert therapeutic effect in a rat model of cavernous nerves injury. Andrology 6, 927-935. doi: 10.1111/andr.12519

Li, S.-D., and Huang, L. (2009). Nanoparticles evading the reticuloendothelial system: role of the supported bilayer. Biochim. Biophys. Acta Biomembranes 1788, 1-10. doi: 10.1016/j.bbamem.2009.06.022

Li, T., Yan, Y., Wang, B., Qian, H., Zhang, X., Shen, L., et al. (2013). Exosomes derived from human umbilical cord mesenchymal stem cells alleviate liver fibrosis. Stem Cells Dev. 22, 845-854. doi: 10.1089/scd.2012.0395

Li, Z., Liu, F., He, X., Yang, X., Shan, F., and Feng, J. (2019). Exosomes derived from mesenchymal stem cells attenuate inflammation and demyelination of the central nervous system in EAE rats by regulating the polarization of microglia. Int. Immunopharmacol. 67, 268-280. doi: 10.1016/j.intimp.2018.12.001

Liao, Z., Wang, W., Deng, W., Zhang, Y., Song, A., Deng, S., et al. (2021). Human umbilical cord mesenchymal stem cells-secreted TSG-6 is anti-inflammatory and promote tissue repair after spinal cord injury. ASN Neuro 13, 2-5. doi: $10.1177 / 17590914211010628$

Limon, J. J., Skalski, J. H., and Underhill, D. M. (2017). Commensal fungi in health and disease. Cell Host Microbe 22, 156-165. doi: 10.1016/j.chom.2017.07.002

Liu, L., Jin, X., Hu, C.-F., Li, R., and Shen, C.-X. (2017). Exosomes derived from mesenchymal stem cells rescue myocardial ischaemia/reperfusion injury by inducing cardiomyocyte autophagy via AMPK and Akt pathways. Cell. Physiol. Biochem. 43, 52-68. doi: 10.1159/000480317

Ma, Z.-J., Yang, J.-J., Lu, Y.-B., Liu, Z.-Y., and Wang, X.-X. (2020). Mesenchymal stem cell-derived exosomes: toward cell-free therapeutic strategies in regenerative medicine. World J. Stem Cells 12:5. doi: 10.4252/wjsc.v12.i8.814

Mao, F., Wu, Y., Tang, X., Kang, J., Zhang, B., Yan, Y., et al. (2017). Exosomes derived from human umbilical cord mesenchymal stem cells relieve inflammatory bowel disease in mice. BioMed Res. Int. 2017:5356760. doi: $10.1155 / 2017 / 5356760$

Nassar, W., El-Ansary, M., Sabry, D., Mostafa, M. A., Fayad, T., Kotb, E., et al. (2016). Umbilical cord mesenchymal stem cells derived extracellular vesicles can safely ameliorate the progression of chronic kidney diseases. Biomater. Res. 20, 1-11. doi: 10.1186/s40824-016-0068-0

Nauta, A. J., and Fibbe, W. E. (2007). Immunomodulatory properties of mesenchymal stromal cells. Blood J. Am. Soc. Hematol. 110:2. doi: 10.1182/blood-2007-02-069716

Netea, M. G., Stuyt, R. J., Kim, S.-H., Van der Meer, J. W., Kullberg, B. J., and Dinarello, C. A. (2002). The role of endogenous interleukin (IL)-18, IL-12, IL- $1 \beta$, and tumor necrosis factor- $\alpha$ in the production of interferon- $\gamma$ induced by Candida albicans in human whole-blood cultures. J. Infect. Dis. 185:2. doi: $10.1086 / 339410$

Ni, H., Yang, S., Siaw-Debrah, F., Hu, J., Wu, K., He, Z., et al. (2019). Exosomes derived from bone mesenchymal stem cells ameliorate early inflammatory responses following traumatic brain injury. Front. Neurosci. 13:14. doi: 10.3389/fnins.2019.00014

Oh, S., Jang, A. Y., Chae, S., Choi, S., Moon, J., Kim, M., et al. (2021). Comparative analysis on the anti-inflammatory/immune effect of mesenchymal stem cell therapy for the treatment of pulmonary arterial hypertension. Sci. Rep. 11:1. doi: 10.1038/s41598-021-81244-1

Pappas, P. G., Lionakis, M. S., Arendrup, M. C., Ostrosky-Zeichner, L., and Kullberg, B. J. (2018). Invasive candidiasis. Nat. Rev. Dis. Prim. 4, 1-20. doi: $10.1038 /$ nrdp. 2018.26 
Park, M. J., Park, H. S., Cho, M. L., Oh, H. J., Cho, Y. G., Min, S. Y., et al. (2011). Transforming growth factor $\beta$-transduced mesenchymal stem cells ameliorate experimental autoimmune arthritis through reciprocal regulation of Treg/Th17 cells and osteoclastogenesis. Arthrit. Rheumat. 63:5. doi: 10.1002/art.30326

Phinney, D. G., and Pittenger, M. F. (2017). Concise review: MSC-derived exosomes for cell-free therapy. Stem Cells 35:2. doi: 10.1002/stem.2575

Prasad, G. (2007). Normal Microbial Flora of Human Body and Host Parasite Relationship. Hisar: CCS Haryana Agricultural University.

Qiu, H., Liu, S., Wu, K., Zhao, R., Cao, L., and Wang, H. (2020). Prospective application of exosomes derived from adipose-derived stem cells in skin wound healing: a review. J. Cosmet. Dermatol. 19, 2-4. doi: 10.1111/jocd.13215

Qu, Q., Pang, Y., Zhang, C., Liu, L., and Bi, Y. (2020). Exosomes derived from human umbilical cord mesenchymal stem cells inhibit vein graft intimal hyperplasia and accelerate reendothelialization by enhancing endothelial function. Stem Cell Res. Ther. 11, 1-14. doi: 10.1186/s13287-020-01639-1

Raposo, G., and Stoorvogel, W. (2013). Extracellular vesicles: exosomes, microvesicles, and friends. J. Cell Biol. 200, 2-6. doi: 10.1083/jcb.201211138

Ratajczak, M., Kucia, M., Jadczyk, T., Greco, N., Wojakowski, W., Tendera, M., et al. (2012). Pivotal role of paracrine effects in stem cell therapies in regenerative medicine: can we translate stem cell-secreted paracrine factors and microvesicles into better therapeutic strategies? Leukemia 26, 1-6. doi: 10.1038/leu.2011.389

Schinocca, C., Rizzo, C., Fasano, S., Grasso, G., La Barbera, L., Ciccia, F., et al. (2021). Role of the IL-23/IL-17 pathway in rheumatic diseases: an overview. Front. Immunol. 12:7. doi: 10.3389/fimmu.2021.637829

Scriven, J. E., Tenforde, M. W., Levitz, S. M., and Jarvis, J. N. (2017). Modulating host immune responses to fight invasive fungal infections. Curr. Opin. Microbiol. 40, 1-5. doi: 10.1016/j.mib.2017.10.018

Sun, Y., Shi, H., Yin, S., Ji, C., Zhang, X., Zhang, B., et al. (2018). Human mesenchymal stem cell derived exosomes alleviate type 2 diabetes mellitus by reversing peripheral insulin resistance and relieving $\beta$-cell destruction. ACS Nano 12, 7613-7628. doi: 10.1021/acsnano.7b07643

Thomi, G., Surbek, D., Haesler, V., Joerger-Messerli, M., and Schoeberlein, A. (2019). Exosomes derived from umbilical cord mesenchymal stem cells reduce microglia-mediated neuroinflammation in perinatal brain injury. Stem Cell Res. Ther. 10, 1-16. doi: 10.1186/s13287-019-1207-z

Vallabhaneni, S., Mody, R. K., Walker, T., and Chiller, T. (2016). The global burden of fungal diseases. Infect. Dis. Clin. 30, 1-11. doi: 10.1016/j.idc.2015.10.004

Wang, Y., Zhang, L., Li, Y., Chen, L., Wang, X., Guo, W., et al. (2015). Exosomes/microvesicles from induced pluripotent stem cells deliver cardioprotective miRNAs and prevent cardiomyocyte apoptosis in the ischemic myocardium. Int. J. Cardiol. 192:4. doi: 10.1016/j.ijcard.2015.05.020

Waterman, R. S., Tomchuck, S. L., Henkle, S. L., and Betancourt, A. M. (2010). A new mesenchymal stem cell (MSC) paradigm: polarization into a proinflammatory MSC1 or an immunosuppressive MSC2 phenotype. PLoS ONE 5:7. doi: 10.1371/journal.pone.0010088

Xu, C., Zhao, J., Li, Q., Hou, L., Wang, Y., Li, S., et al. (2020a). Exosomes derived from three-dimensional cultured human umbilical cord mesenchymal stem cells ameliorate pulmonary fibrosis in a mouse silicosis model. Stem Cell Res. Ther. 11, 1-12. doi: 10.1186/s13287-02002023-9

Xu, L., Ji, H., Jiang, Y., Cai, L., Lai, X., Wu, F., et al. (2020b). Exosomes derived from circAkap7-modified adipose-derived mesenchymal stem cells protect against cerebral ischemic injury. Front. Cell Dev. Biol. 8:1066 doi: $10.3389 /$ fcell.2020.569977

Yáñez, M.-M.ó., Siljander, P. R.-M., Andreu, Z., Bedina Zavec, A., Borràs, F. E., Buzas, E. I., et al. (2015). Biological properties of extracellular vesicles and their physiological functions. J. Extracell. Vesic. 4:3. doi: 10.3402/jev.v4.27066

Yang, R., Liu, Y., Kelk, P., Qu, C., Akiyama, K., Chen, C., et al. (2013). A subset of IL-17+ mesenchymal stem cells possesses anti-Candida albicans effect. Cell Res. 23:1. doi: 10.1038/cr.2012.179

Yao, Y., Chen, R., Wang, G., Zhang, Y., and Liu, F. (2019). Exosomes derived from mesenchymal stem cells reverse EMT via TGF- $\beta 1 /$ Smad pathway and promote repair of damaged endometrium. Stem Cell Res. Ther. 10, 1-17. doi: 10.1186/s13287-019-1332-8

Zhang, B., Tian, X., Hao, J., Xu, G., and Zhang, W. (2020a). Mesenchymal stem cell-derived extracellular vesicles in tissue regeneration. Cell Transpl. 29:2. doi: 10.1177/0963689720908500

Zhang, C., Zhang, C., Xu, Y., Li, C., Cao, Y., and Li, P. (2020b). Exosomes derived from human placenta-derived mesenchymal stem cells improve neurologic function by promoting angiogenesis after spinal cord injury. Neurosci. Lett. 739:135399. doi: 10.1016/j.neulet.2020.135399

Zhang, S., Chu, W., Lai, R., Lim, S., Hui, J., and Toh, W. (2016). Exosomes derived from human embryonic mesenchymal stem cells promote osteochondral regeneration. Osteoarthrit. Cartilage 24, 2135-2140. doi: 10.1016/j.joca.2016.06.022

Zhao, S., Qi, W., Zheng, J., Tian, Y., Qi, X., Kong, D., et al. (2020). Exosomes derived from adipose mesenchymal stem cells restore functional endometrium in a rat model of intrauterine adhesions. Reprod. Sci. 2020, 1-10. doi: 10.1007/s43032-019-00112-6

Zhou, W., and Xu, Y. (2020). "Application of Mesenchymal Stem Cells in Human Diseases. Mesenchymal Stem Cells in Human Health and Diseases," in Mesenchymal Stem Cells in Human Health and Diseases, ed A. H. K. El-Hashash (London: Elsevier), 5-15. doi: 10.1016/B978-0-12-819713-4.00002-5

Zhu, Y., Jia, Y., Wang, Y., Xu, J., and Chai, Y. (2019). Impaired bone regenerative effect of exosomes derived from bone marrow mesenchymal stem cells in type 1 diabetes. Stem Cells Transl. Med. 8, 593-605. doi: 10.1002/sctm.1 8-0199

Conflict of Interest: The author declares that the research was conducted in the absence of any commercial or financial relationships that could be construed as a potential conflict of interest.

Publisher's Note: All claims expressed in this article are solely those of the authors and do not necessarily represent those of their affiliated organizations, or those of the publisher, the editors and the reviewers. Any product that may be evaluated in this article, or claim that may be made by its manufacturer, is not guaranteed or endorsed by the publisher.

Copyright (ㄷ) 2021 Ghasemian. This is an open-access article distributed under the terms of the Creative Commons Attribution License (CC BY). The use, distribution or reproduction in other forums is permitted, provided the original author(s) and the copyright owner(s) are credited and that the original publication in this journal is cited, in accordance with accepted academic practice. No use, distribution or reproduction is permitted which does not comply with these terms. 